\title{
A Study on the Minimum Paste Volume in the Design of Concrete Mixture
}

\author{
David W. Fowler, ${ }^{1)}$ Michael De Moya Hahn, ${ }^{1)}$ Marc Rached, ${ }^{1)}$ Doo-Sun Choi, ${ }^{2)}$ \\ and Jae-Jin Choi ${ }^{3)}$
}

(Received May 29, 2008, Revised September 24, 2008, Accepted October 31, 2008)

\begin{abstract}
Optimization of concrete mixing system is very important for the production of quality mixture of concrete and requires very complicated, specialized knowledge as there are a variety of variables that influence the result. One of the methods of optimizing the concrete mixing system is to minimize the volume of cement paste which, in turn, means maximizing the volume of aggregate. The purpose of this study is to determine the minimum volume of cement paste used in the design of concrete mixture and to design the optimum concrete mixing system based on the fluidity of mortar and concrete. In determining the minimum volume of cement paste, experiments of mortar and concrete were performed based on their workability, material segregation and bleeding. Type of aggregate, granularity distribution and sand percentage were used as test parameters and measurements were taken of the distribution of granularity, usage of HRWRA, minimum volume of paste and drying shrinkage and compressive strength of concrete.
\end{abstract}

Keywords: minimum paste volume, granularity of aggregate, fluidity, drying shrinkage, compressive strength

\section{Introduction}

Changing environment of construction including regulations on greenhouse gas emission, the shortage of natural aggregates and increase of the use of crushed aggregate spurred a number of active studies on finding the ways of increasing the usage of aggregate, the main component of concrete, and reducing the requirement of binder while maintaining certain level of the quality of concrete. ${ }^{1-5}$

The volume of concrete consists of $65-80 \%$ of aggregate and $15-$ $30 \%$ of water and binder (cement and mineral admixture). The properties of aggregate, in particular, has crucial effect on the performance of fresh and hardened concrete as well as on the cost of concrete production.

Therefore, optimizing the concrete mixing system is very important for the production of high quality concrete. As the optimization of concrete mixing system depends on a variety of variables, it requires very complicated specialist knowledge, and the optimum mixture of concrete should not be construed as 'the' solution to universal purposes.

While cement is the most expensive ingredient of concrete,

\footnotetext{
${ }^{1)}$ Dept. of Civil, Architectural \& Environmental Engineering, The University of Texas at Austin, Austin, TX 78712-0277, USA.

${ }^{2)}$ KCI Member, Dept. of Research \& Development, Dasan Global Consulting Co., Ltd., Suwon 440-852, Korea.

${ }^{3)}$ KCI Member, Dept. of Civil \& Environmental Engineering, Kongju National University, Cheonan 330-717, Korea.

E-mail: jjchoi@kongju.ac.kr

Copyright (c) 2008, Korea Concrete Institute. All rights reserved, including the making of copies without the written permission of the copyright proprietors.
}

aggregate is the cheapest one except for the mixing water. Cement paste fills the voids among the granules of aggregate, binds them together and renders fluidity of concrete before hardening, but it also causes such problems as drying shrinkage and hydration heat. One solution to the optimization of concrete should therefore be the minimization of the volume of cement paste which also means maximization of the volume of aggregate.

The purpose of this study is to determine the minimum volume of cement paste used in the design of concrete mixture and to design the optimum concrete mixing system based on the fluidity of mortar and concrete.

In order to determine the minimum volume of cement paste, tests were performed on mortar and concrete based on their workability, material segregation and bleeding.

In mortar experiment, the target flow value of mortar was set at 130 considering the fluidity of concrete and, in concrete experiment, target slump was set at $15 \pm 2.5 \mathrm{~cm}$ for concrete fluidity, then the effects of aggregate on the properties of concrete were intensely examined. Also, drying shrinkage and strength characteristics relative to the distribution of granularity were analyzed.

\section{Experimental program}

\subsection{Materials}

\subsubsection{Cement}

All mortar and concrete mixes incorporated the same variety of Type I Portland cement conforming to ASTM specifications C 150. Table 1 shows the chemical and physical properties of the cement. 
Table 1 Chemical and physical properties of cement.

\begin{tabular}{c|c|c|c|c|c|c|c|c|c}
\hline \multicolumn{8}{c|}{ Chemical composition (\%) } & \multicolumn{3}{c}{ Physical properties } \\
\hline \hline $\mathrm{SiO}_{2}$ & $\mathrm{Al}_{2} \mathrm{O}_{3}$ & $\mathrm{Fe}_{2} \mathrm{O}_{3}$ & $\mathrm{CaO}$ & $\mathrm{MgO}$ & $\mathrm{SO}_{3}$ & $\mathrm{Na}_{2} \mathrm{O}_{\text {eq }}$ & Ig. loss & Density $\left(\mathrm{g} / \mathrm{cm}^{3}\right)$ & $\mathrm{Blaine}\left(\mathrm{cm}^{2} / \mathrm{g}\right)$ \\
\hline 20.2 & 4.6 & 3.1 & 64.9 & 1.4 & 2.8 & 0.42 & 2.07 & 3.15 & 3,790 \\
\hline
\end{tabular}

\subsubsection{Chemical admixture}

In order to achieve the target flow of 130 and target slump of $15 \pm 2.5 \mathrm{~cm}$, Glenium $3030 \mathrm{NS}$, high-range water reducer admixture (HRWRA) of polycarboxylate was used to produce mortar and concrete. The physical properties of HRWRA can be seen in Table 2.

\subsubsection{Aggregate}

The aggregates used consist of two types of fine aggregates, crushed fine aggregate $(\mathrm{Sg})$ and river sand $(\mathrm{Sn})$, and two types of coarse aggregates, river gravels (Gn) and crushed aggregate (Gc). The weight ratio of microfine particles that passed through the \#200 sieve was $1.2 \%$ and 5.3\%, respectively, for Sn and Sg. The physical properties of the aggregates used are shown in Table 3.

\subsection{Mixtures}

\subsubsection{Mortar}

In order to determine the minimum paste volume (MPV) of mortar within the range of the conformity with the target flow of 130 , total 32 batches of mortar mixtures were tested at levels of water-powder volume ratios (W/P) of 1.0, 1.4, 1.8 and 2.2. The values of W/P and the composition of the mixture for each type of aggregates at MVP are as shown in Table 4. The powder volume here indicates the total volume of cement and fine aggregate that passed through the \#200 sieve and the paste volume indicates the total volume of powder, water and HRWRA in percentage of the volume of each batch.

\subsubsection{Concrete}

In order to examine the effects of different combination of aggregate on the characteristics of concrete, 12 batches of concrete mixtures were tested for each of the three types of combined aggregates of river sand and river gravels ( $\mathrm{N}$-series), crushed fine aggregate and river gravel (G-series), and river sand and crushed coarse aggregate (M-series). The concrete mix was prepared by applying fixed water-cement ratio of $50 \%$ to 3 levels of sand percentage (S/a) of $30 \%, 40 \%$ and $50 \%$. Mix proportions were determined (designed) in accordance with ACI 211 specification. The concrete mixtures that conform to MPV among total 36 batches are listed in Table 5.

Concrete mixing and preparation of specimens were carried out conforming to ASTM specification C 192: to prepare concrete, cement, water and aggregates were mixed first for three minutes, and slump of concrete was measured. When target slump was not achieved, HRWRA was added and further mixing was done for two minutes.

Three concrete specimens were prepared each for compressive strength test (size $100 \times 200 \mathrm{~mm}$ ) and length change test (size $75 \times 75 \times 300 \mathrm{~mm}$ ) for each of the batches.

The temperature during the casting of specimens was maintained at $23 \pm 2^{\circ} \mathrm{C}$.

\subsection{Test methods}

\subsubsection{Grading of aggregates}

In order to examine the effects of the shape and grading of the

Table 2 Physical property of HRWRA.

\begin{tabular}{c|c|c|c|c|c|c}
\hline Color & Physical state & $\mathrm{pH}$ & Density $\left(\mathrm{g} / \mathrm{cm}^{3}\right)$ & Water solubility & Boiling point $\left({ }^{\circ} \mathrm{C}\right)$ & Freeze point $\left({ }^{\circ} \mathrm{C}\right)$ \\
\hline \hline Brown & Liquid & 58 & $1.05 \pm 0.05$ & Completely & 100 & -1 \\
\hline
\end{tabular}

Table 3 Physical properties of aggregates.

\begin{tabular}{|c|c|c|c|c|c|c|c|c|c|}
\hline & \multirow{2}{*}{ Mineralogy } & \multirow{2}{*}{ F.M. } & \multirow{2}{*}{$\begin{array}{l}\text { Microfine } \\
(\%)\end{array}$} & \multirow{2}{*}{$\begin{array}{c}\text { Density }\left(\mathrm{g} / \mathrm{cm}^{3}\right) \\
(\mathrm{SSD} / \mathrm{OD})\end{array}$} & \multirow{2}{*}{$\begin{array}{c}\text { Absorption } \\
(\%)\end{array}$} & \multirow{2}{*}{$\begin{array}{l}\text { Unit weight } \\
\left(\mathrm{kg} / \mathrm{m}^{3}\right)\end{array}$} & \multirow{2}{*}{$\begin{array}{c}\text { Packing } \\
\text { density(\%) }\end{array}$} & \multicolumn{2}{|c|}{$\mathrm{CPA}$} \\
\hline & & & & & & & & Sphericity & Length/Width \\
\hline 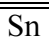 & "River sand & 2.58 & 1.2 & $2.60 / 2.58$ & 0.54 & $1,1,744$ & 67.6 & 1.085 & 1.452 \\
\hline $\mathrm{Sg}$ & Limestone & 2.76 & 5.3 & $2.61 / 2.57$ & 1.62 & 1,709 & 66.6 & 1.126 & 1.492 \\
\hline Gn & River gravel & 6.47 & - & $2.59 / 2.56$ & 1.30 & - & - & - & - \\
\hline $\mathrm{Gc}$ & Limestone & 6.66 & - & $2.59 / 2.55$ & 1.43 & 1,496 & 58.6 & 1.112 & 1.432 \\
\hline
\end{tabular}

Table 4 Mix proportions of mortar.

\begin{tabular}{c|c|c|c|c|c|c}
\hline \multirow{2}{*}{ Types } & \multirow{2}{*}{ W/P } & \multicolumn{4}{|c|}{ Batch quantities (g/l) } & \multirow{2}{*}{ Minimum paste volume (\%) } \\
\cline { 2 - 7 } & & $\mathrm{S}$ & $\mathrm{C}$ & $\mathrm{W}$ & HRWRA & 37.4 \\
\hline \hline \multirow{3}{*}{ MSn } & 1.0 & 1,740 & 526 & 184 & 44.51 & 36.6 \\
\cline { 2 - 7 } & 1.4 & 1,688 & 435 & 213 & 24.93 & 35.8 \\
\cline { 2 - 7 } & 1.8 & 1,688 & 369 & 234 & 12.53 & 35.5 \\
\hline \multirow{3}{*}{ MSg } & 2.2 & 1,688 & 320 & 250 & 8.12 & 40.5 \\
\cline { 2 - 7 } & 1.0 & 1,654 & 507 & 222 & 27.18 & 40.2 \\
\cline { 2 - 7 } & 1.4 & 1,654 & 404 & 255 & 20.28 & 39.5 \\
\hline
\end{tabular}


Table 5 Mix proportions of concrete.

\begin{tabular}{|c|c|c|c|c|c|c|c|c|c|c|}
\hline & \multirow{3}{*}{$\begin{array}{l}\mathrm{W} / \mathrm{C} \\
(\%)\end{array}$} & \multirow{3}{*}{$\begin{array}{l}\text { S/a } \\
(\%)\end{array}$} & \multicolumn{7}{|c|}{ Unit weight $\left(\mathrm{kg} / \mathrm{m}^{3}\right)$} & \multirow{3}{*}{$\begin{array}{c}\text { Minimum paste } \\
\text { volume (\%) }\end{array}$} \\
\hline & & & \multirow{2}{*}{ W } & \multirow{2}{*}{$\mathrm{C}$} & \multicolumn{2}{|c|}{$\mathrm{S}$} & \multicolumn{2}{|c|}{ G } & \multirow{2}{*}{ HRWRA } & \\
\hline & & & & & $\mathrm{Sn}$ & $\mathrm{Sg}$ & $\mathrm{Gn}$ & $\mathrm{Gc}$ & & \\
\hline N30 & 50 & 30 & 147 & 293 & 577 & & 1,341 & & 1.44 & 27.3 \\
\hline $\mathrm{N} 40$ & 50 & 40 & 150 & 300 & 764 & & 1,142 & & 1.51 & 27.9 \\
\hline N50 & 50 & 50 & 147 & 293 & 962 & & 958 & & 2.01 & 28.1 \\
\hline G30 & 50 & 30 & 147 & 293 & & 579 & 1,341 & & 1.29 & 28.0 \\
\hline G40 & 50 & 40 & 147 & 293 & & 772 & 1,149 & & 1.15 & 28.9 \\
\hline G50 & 50 & 50 & 147 & 293 & & 965 & 958 & & 2.88 & 30.5 \\
\hline M30 & 50 & 30 & 156 & 312 & 565 & & & 1,314 & 0.65 & 27.9 \\
\hline M40 & 50 & 40 & 141 & 281 & 780 & & & 1,165 & 1.44 & 28.3 \\
\hline M50 & 50 & 50 & 135 & 269 & 988 & & & 984 & 5.17 & 29.4 \\
\hline
\end{tabular}

aggregate particles on concrete, tests were performed on unit weight, packing density and sieve analysis. 0.45 -power curve and percent retained chart were used to analyze the properties of the aggregates.

\subsubsection{Workability of mortar and concrete}

In order to determine the workability of mortar and concrete, mortar flow test and concrete slump test were performed conforming to ASTM specification C 230 and C 143 respectively. The quantity of HRWRA required to maintain target flow of 130 and target slump of $15 \pm 2.5 \mathrm{~cm}$ was also measured.

\subsubsection{Drying shrinkage of concrete}

The changes in concrete length were measured for each aging stage on day $7,11,14,21,35,63$ and 119 conforming to ASTM specification C490 to determine the effects of the type of aggregate, distribution of grading and the used volume of HRWRA on drying shrinkage of concrete.

\subsubsection{Compressive strength of concrete}

In order to determine the effects of the type of aggregate, distribution of grading and the used volume of HRWRA on the compressive strength of concrete, compressive strength of the concrete was measured on day 28 conforming to ASTM specification C 39. The specimen for compressive strength test was demolded after 24 hours and transferred to the fog room for wet-curing until it reached the specified age.

\section{Results and discussion}

\subsection{Grading properties of aggregates}

The bad grading of the aggregate particles, as well as inadequate mixture, has critical effect on the workability and durability of concrete. ${ }^{6}$ However, the grading of the aggregate is usually examined simply by using the standard grading distribution curve. Therefore, we used not only the standard grading distribution curve, but percent remained chart and 0.45 -power curve as well to determine the grading properties of aggregates.

The percent remained chart mostly indicates grading distribution characteristics of aggregate mixture used for concrete and it indicates the remaining percent of aggregate in each sieve for each size of the sieves. ${ }^{7,8}$

Fig. 1 shows the grading distribution of the two types of fine aggregates used in the mortar tests, as determined using the percent retained chart.

Both of the two types of aggregates satisfied the standard grading distribution of fine aggregate. Grain size of $0.3 \sim 0.6 \mathrm{~mm}$ formed the largest distribution of $32.5 \%$ in river sand and the highest distribution in crushed fine aggregate consisted of grain size $1.2 \sim 2.5 \mathrm{~mm}$ which took up $33.7 \%$.

The grading distribution of combined aggregate for concrete mixes which have sand percentage (S/a) of $40 \%$ are shown in Fig. 2.

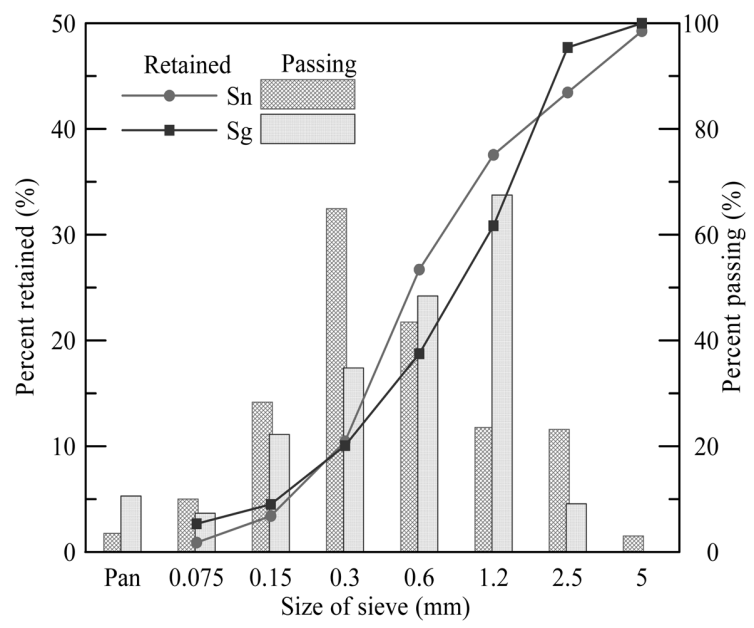

Fig. 1 Percent retained chart of fine aggregates.

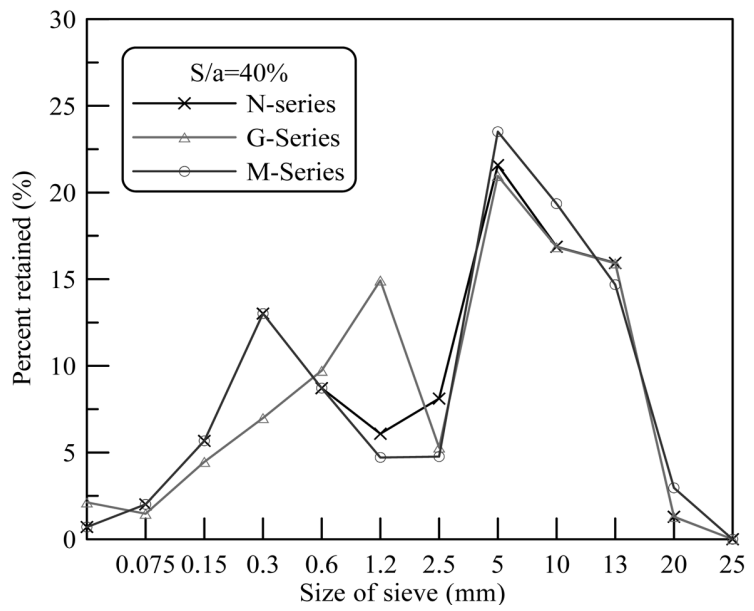

Fig. 2 Percent retained chart of combined aggregates. 
As shown in the figure, compared with the N-series and Mseries, the G-series has relatively more fine aggregates of size larger than $0.6 \mathrm{~mm}$. In M-series, which contains crushed coarse aggregate, has relatively more particles of size $5 \sim 13 \mathrm{~mm}$ than the other combination of aggregates.

The 0.45-power curve was mainly used in the design of asphalt mixture. It was represented in a coordinate where the value of each sieve size divided by the size of the largest sieve and powered by $0.45\left(d_{i} / \mathrm{D}\right)^{0.45}$ was plotted on $\mathrm{x}$-axis and the weight percent of the cumulative aggregate that passed through each sieve was plotted on y-axis. The 0.45-power curve, however, is currently often used in the design of Portland cement concrete mixture. The closer the cumulative aggregate that passed through each sieve is to the 0.45 -power curve, the more uniform the grading distribution of the aggregate is.

Fig. 3 shows the 0.45 -power curve of combined aggregate used in concrete mixes. It can be seen that there are differences in aggregate distribution in each S/a compared with baseline of the 0.45-power curve.

The concrete mixes with S/a 30\%, of which fine aggregates of less than $5 \mathrm{~mm}$ were mainly positioned below the baseline (Fig. 3(a)), and appeared by visual examination to have rocky characteristics lacking fine aggregate proportion, while other concrete mixes with S/a 50\% above the baseline (Fig. 3(c)) showed more proportion of sandy aggregate.

The concrete mixes with $\mathrm{S} / \mathrm{a} 40 \%$ of which grading distribution of fine aggregates were densely located close to the baseline (Fig. 3(b)) showed good quality characteristics in rheology, bleeding and material segregation.

\subsection{Workability of mortar and concrete}

Dosage of HRWRA in MPV used in mortar test to achieve target flow of 130 is shown in Fig. 4. HRWRA dosage tends to decrease as W/P increases regardless of the type of aggregate as shown in Fig. 4(a), which is thought to be the result of relatively larger proportion of cement used when W/P is low. In the same $\mathrm{W} / \mathrm{P}$, the more HRWRA was used in mortar MSn containing river sand than the mortar MSg containing crushed fine aggregate.

As shown in the relationship between MPV and HRWRA usage in Fig. 4(b), HRWRA dosage in different types of fine aggregates varied significantly. HRWRA dosage decreased linearly in proportional to the decrease in the volume of paste. It is because viscosity of paste was lower when W/P was larger as the cement content in the paste volume decreased which, in turn, caused relative increase of the flow of paste.

Fig. 5 shows the analysis of the relationship between the volume of cement or water and HRWRA dosage used to maintain the target the flow of 130 in mortar mixture. As can be seen from this figure, there was no particular correlations between the volume of HRWRA and cement content or water content. However, in the MPV of mortar, HRWRA dosage showed linear increased as the cement content increased (Fig. 5(a)) or as the water content decreased (Fig. 5(b)).

These results indicate that the dosage of HRWRA, used to achieve target flow in MPV of mortar, depends more on the volume of cement and water content than on the type of aggregate.

Fig. 6 shows HRWRA dosage in each concrete mix in MPV. HRWRA dosage used to achieve the target slump was lowest

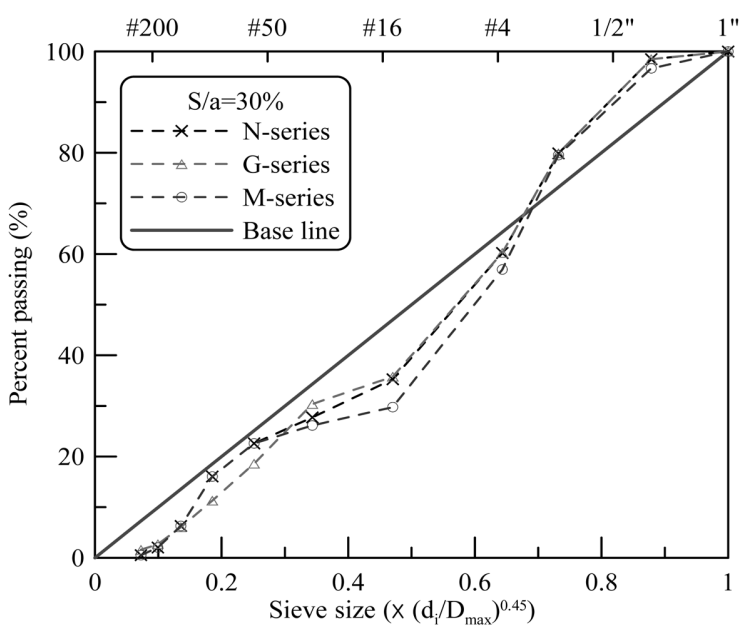

(a) $\mathrm{S} / \mathrm{a}=30 \%$

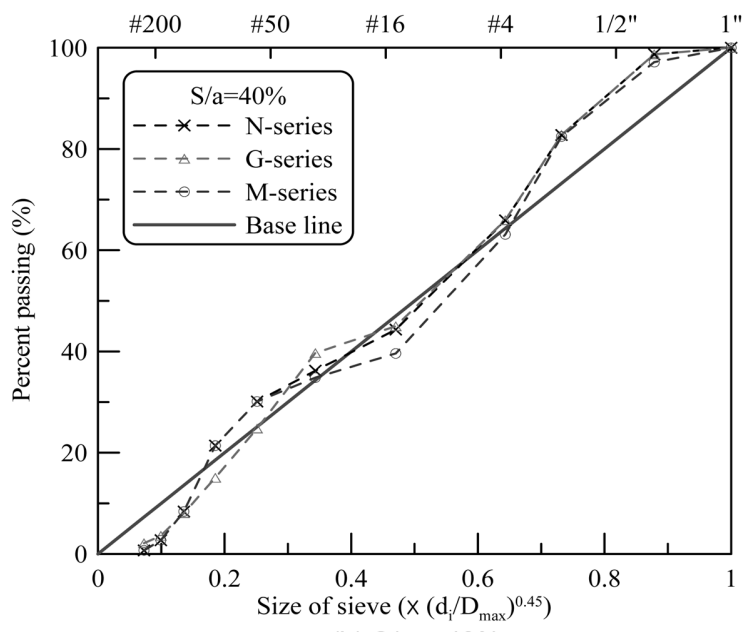

(b) $S / a=40 \%$

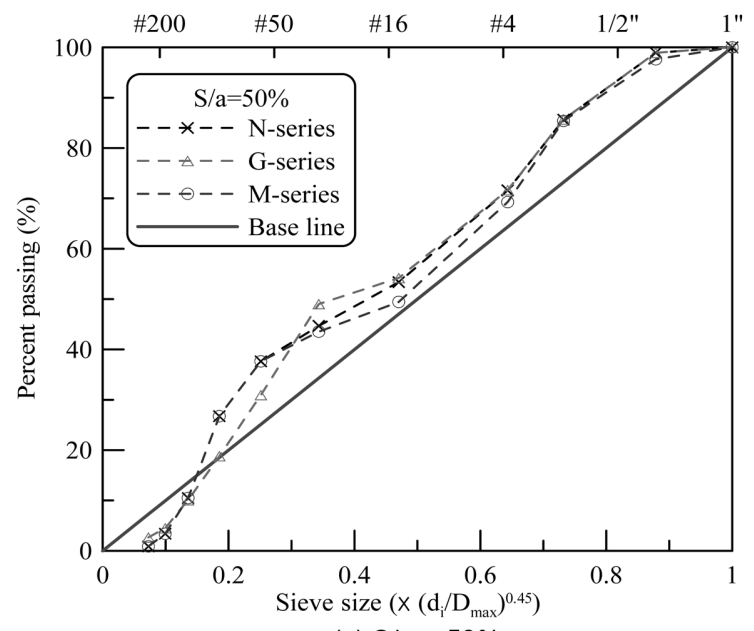

(c) $\mathrm{S} / \mathrm{a}=50 \%$

Fig. 3 0.45-power curve of combined aggregates.

when sand percentage was $40 \%$ regardless of the type of aggregate. In the case of N-series concrete mixes using only the natural aggregates, HRWRA dosage did not show much variance regardless of the sand percentage (S/a). However, in G-series and Mseries, which contained both natural and crushed aggregates, HRWRA dosage used to maintain the target slump of concrete when S/a was $50 \%$ increased significantly by more than $1 \%$ of cement weight. 


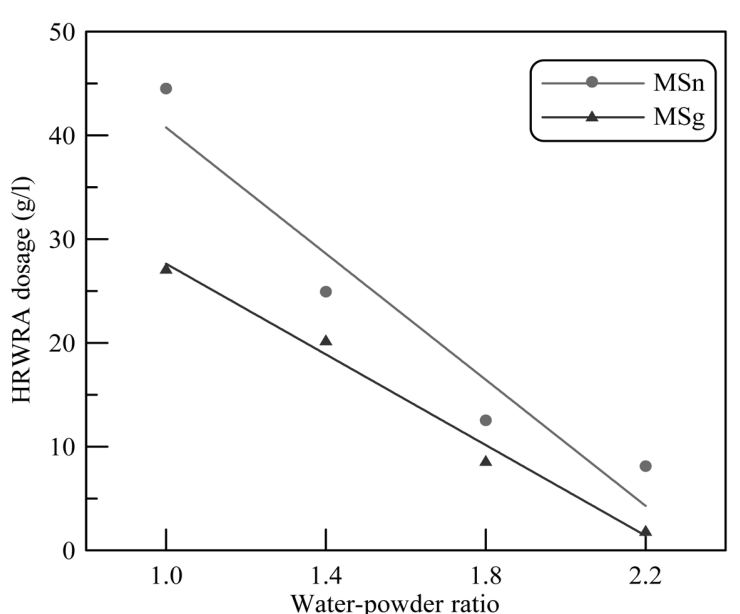

(a) W/P vs. HRWRA dosage

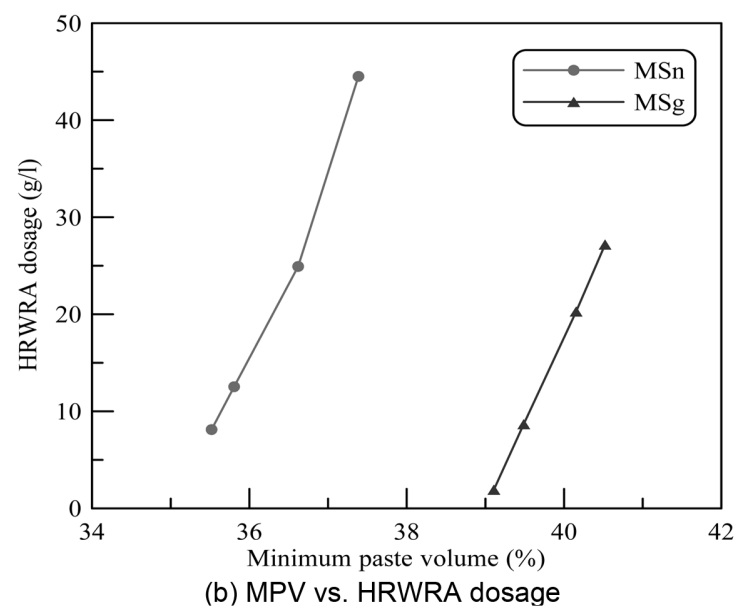

Fig. 4 HRWRA dosage of MPV mortar.

\subsection{Minimum paste volume (MPV)}

The MPV of 32 batches of mortar were plotted relative to the W/P in Fig. 7(a). In this figure, the quality of mortar can be distinguished by the relative position to the MPV lines. Specifically, in all the mortars that satisfy the target flow, the part above the line showed good quality while the other part below the line showed problems in quality due to serious bleeding and material segregation.

The level of MPV in MSn mixture containing natural river sand was 3.5\% lower than the MPV in MSg where crushed aggregates were used. It is thought that it was because $\mathrm{Sg}$ contained microfine particles $4.1 \%$ more than $\mathrm{Sn}$.

It can also be explained by the difference in the shape of the particles in the aggregates used. In other words, as the sphericity of $\mathrm{Sn}$ and $\mathrm{Sg}$ was 1.085 and 1.126 respectively, the particles of Sn, which were closer to the spherical shape, more effectively played the role of ball bearings in the aspect of the flow of mortar decreasing interlocking among the aggregates. On the other hand, the MPV of mortar decreased in a similar pattern to the pattern in which W/P increased regardless of the type of aggregate.

The MPV of total 36 batches of concrete mixes was plotted relative to the sand percentage in Fig. 7(b). The MPV of concrete showed difference for each type of aggregate and the quality of concrete indicated by the relative position to the MPV lines showed a similar pattern to the pattern that the mortar showed. The MPV of concrete containing river gravel was lower in N-

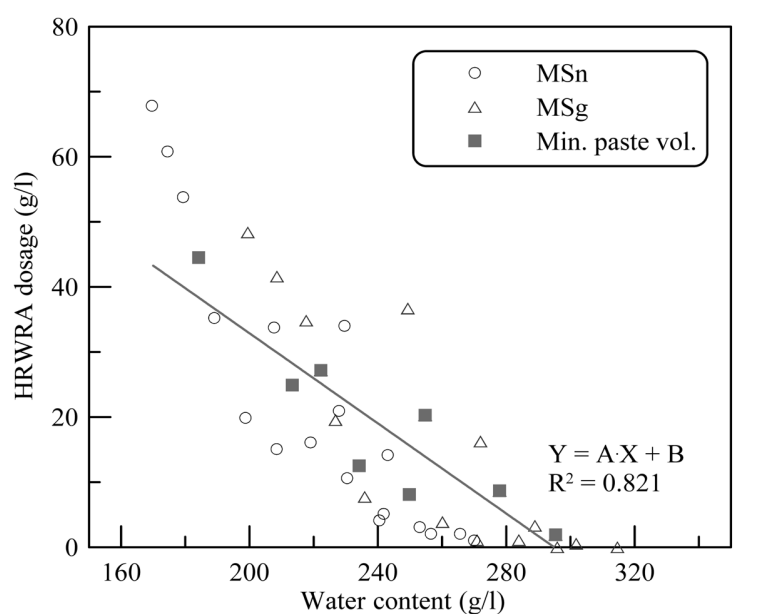

(a) Water content vs. HRWRA dosage

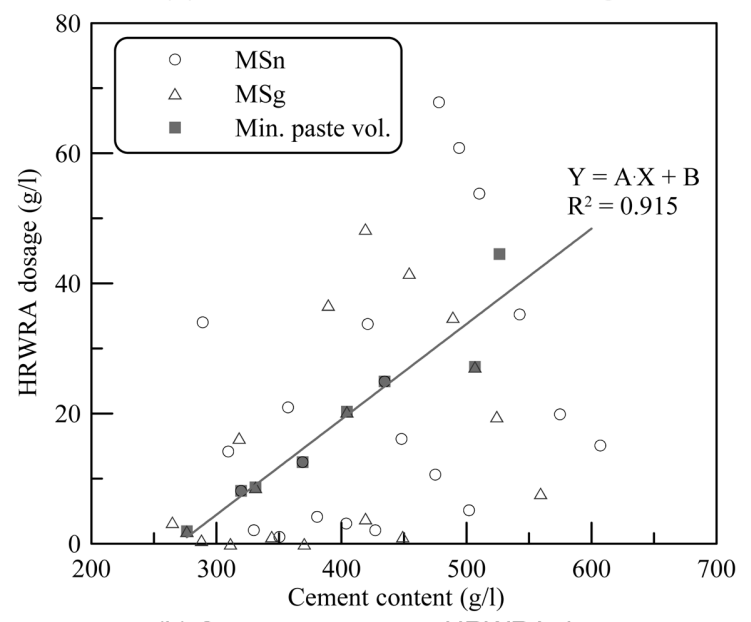

(b) Cement content vs. HRWRA dosage

Fig. 5 HRWRA dosage of mortar.

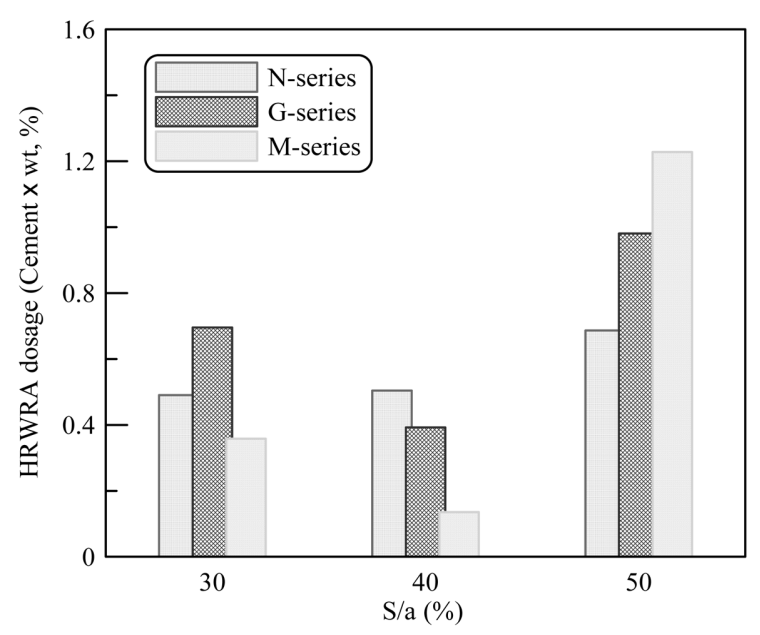

Fig. 6 HRWRA dosage of MPV concretes.

series containing river sand compared with the G-series containing crushed fine aggregates, which also was the similar result to the result with mortar.

However, for the concrete mixes containing river sand, MPV in $\mathrm{N}$-series was lower than in M-series and the MPV of concrete increased as sand percentage increased. Compared with $\mathrm{N}$-series concrete mixes, the MPV of G-series and N-series concrete increased significantly as sand percentage increased. 


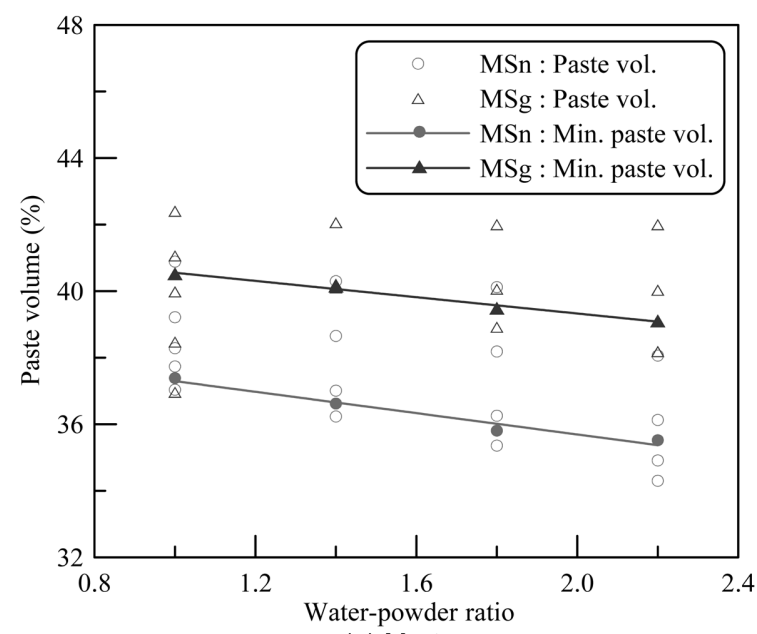

(a) Mortar

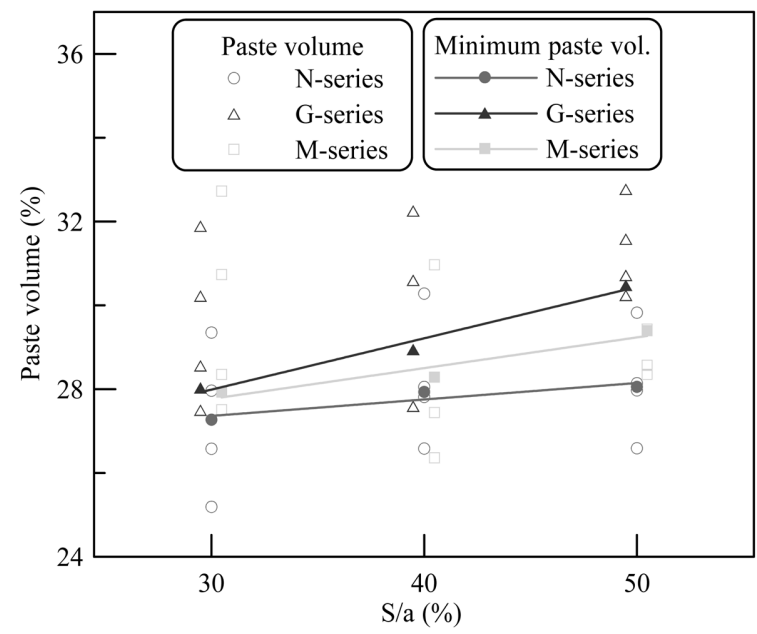

(b) Concrete

Fig. 7 Minimum paste volume of mortar and concrete.

From these results of concrete test, it was found that the MPV of concrete mixes that showed good quality in the aspects of slump, bleeding and material segregation fell within the range of $27.3 \sim 30.5 \%$.

\subsection{Drying shrinkage of concrete}

Fig. 8 shows the result of measuring drying shrinkage of concrete at the age of 119 days. The drying shrinkage of concrete tends to increase as it ages and the length change during the initial stage until the age of 28 days was lowest in M-series containing crushed aggregates. There was no obvious trend between combined aggregate and the content of fine aggregate and the length change of concrete. Length change in long-term age was within the range of $-350 \sim 600 \times 10^{-6} \mathrm{~mm}$ in all concrete mixes.

The correlations between length change of concrete and paste volume and between length change and HRWRA dosage are shown in Fig. 9. The analysis of correlation between length change of concrete and paste volume (Fig. 9(a)) and between length change of concrete and HRWRA dosage (Fig. 9(b)) was performed at the age of 119 days and the results did not show any significant correlation.

\subsection{Compressive strength of concrete}

The compressive strength of concrete with MPV measured for each combination of mixture at the age of 28 days is summarized

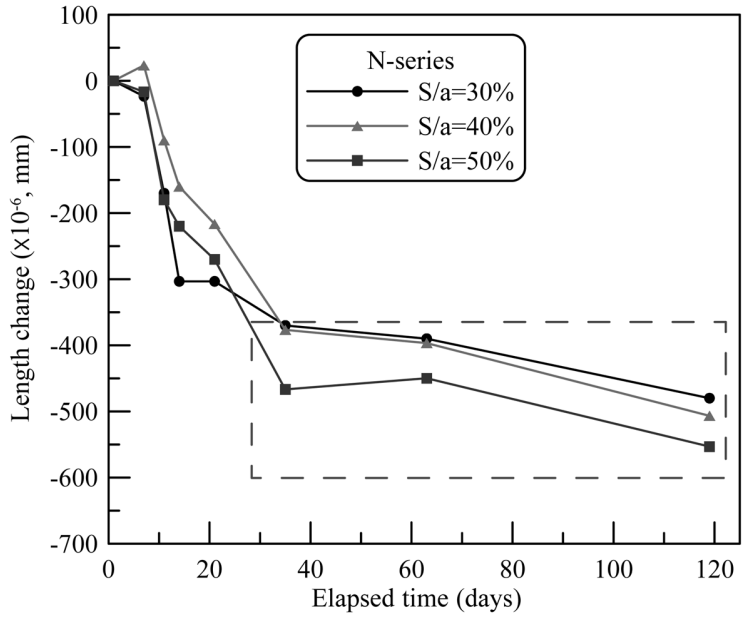

(a) $\mathrm{N}$-series

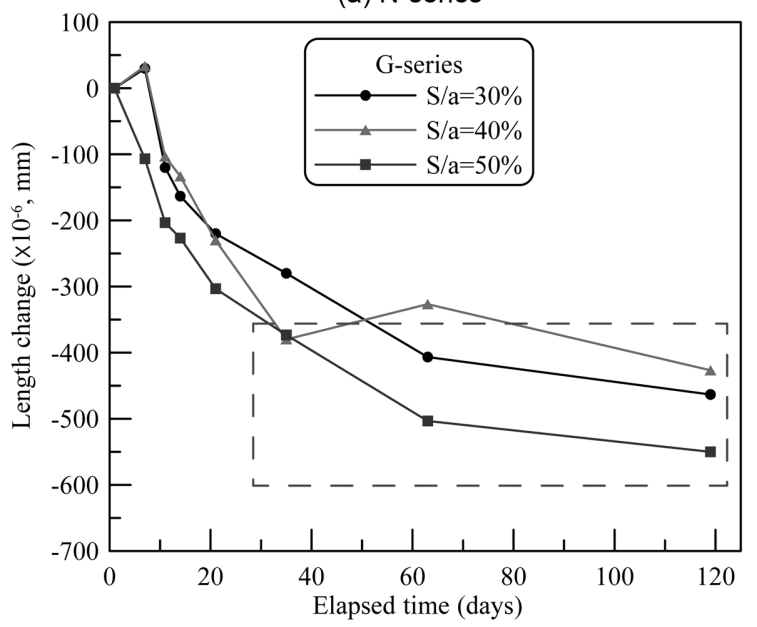

(b) G-series

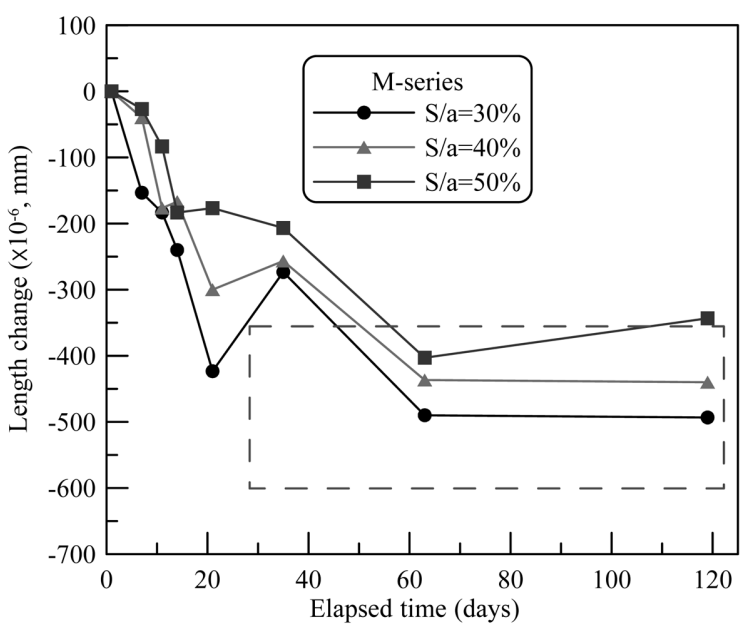

(c) M-series

Fig. 8 Drying shrinkage of MPV concretes.

in Figure 10. All the concrete mixes except for those with $50 \%$ of S/a showed similar compressive strength characteristics in MPV regardless of the types of combined aggregates.

The compressive strength of good quality concretes except MPV concretes with $50 \%$ of S/a showed similar or higher compressive strength compared with the concrete mixes with $30 \%$ and $40 \%$ of S/a. The compressive strength measured for each type of aggregate showed generally higher values in M-series while the concrete mixes in $\mathrm{N}$-series and $\mathrm{G}$-series did not show significant difference. 


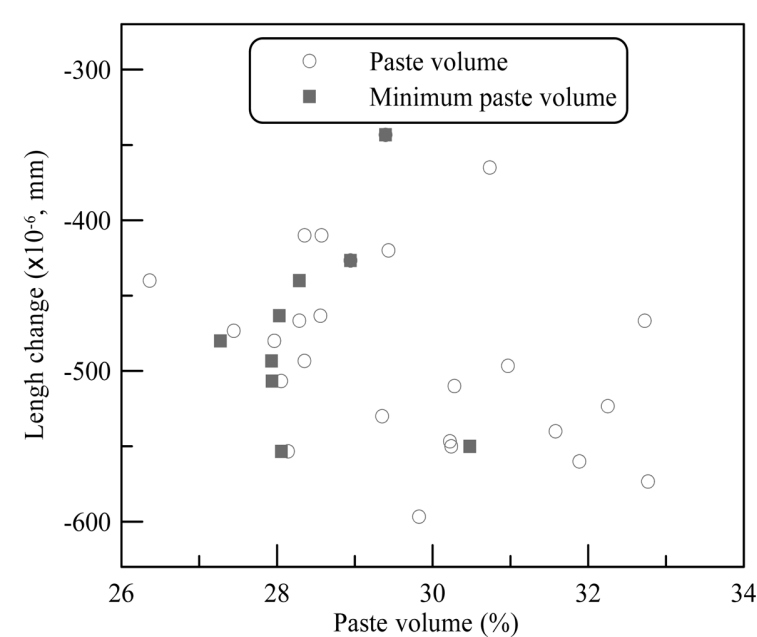

(a) Length change vs. MPV

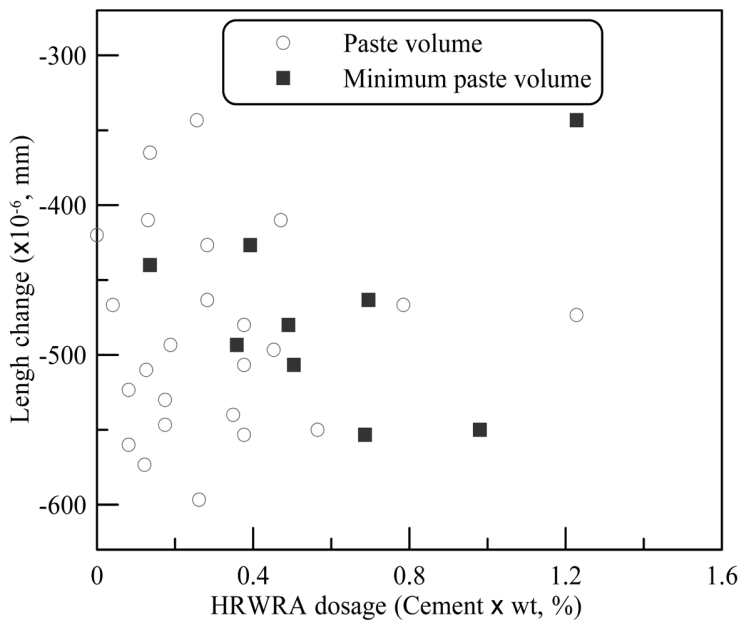

(b) Length change vs. HRWRA dosage

Fig. 9 Relationship length change of concretes and MPV and HRWRA dosage.

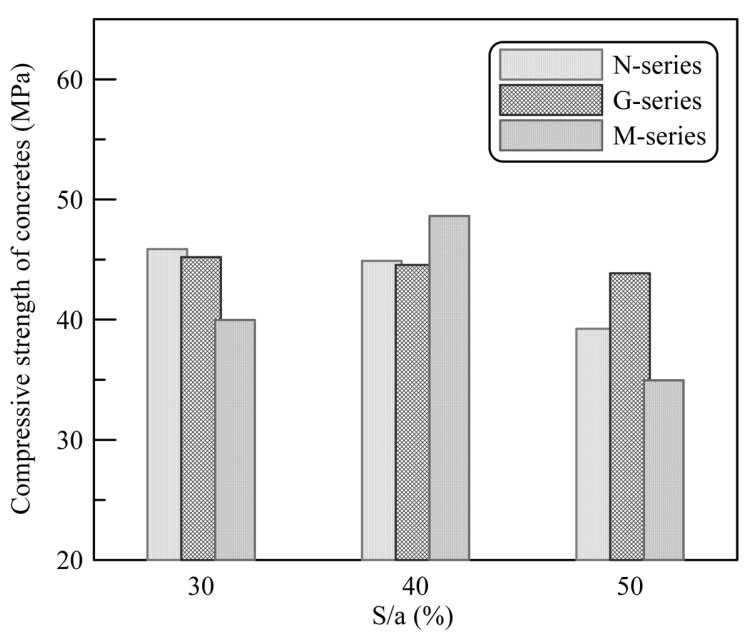

Fig. 10 Compressive strength of MPV concretes.

\section{Conclusions}

The properties of mortar and concrete mixes were analyzed for different types of aggregate, grading distributions and fine aggregate ratios and the results were as follows:
1) The results of mortar test showed linear decrease of HRWRA dosage as water-powder ratio increased. At the same water-powder ratio, HRWRA dosage of mortar containing river sand was used more than that of mortar containing crushed fine aggregates. The analysis of mortar with minimum paste volume indicated that HRWRA dosage used to achieve the target flow was more dependent on cement and water content than the type of aggregate.

2) The minimum paste volume of mortar decreased linearly when water-powder ratio increased and the minimum paste volume of mortar containing river sand was $35.5 \sim 37.4 \%$ which was approximately $3.5 \%$ lower than $39.0 \sim 40.5 \%$ of mortar containing crushed fine aggregate.

3) The minimum paste volume of concrete was larger when sand percentage was higher. Compared with the concrete containing natural aggregate, the minimum paste volume of concrete containing crushed aggregate significantly increased with increasing sand percentage. The minimum paste volume of concrete with good slump, bleeding and material segregation quality was about $27.3 \sim 30.5 \%$.

4) All the mortar and concrete had high quality property such as workability, bleeding and segregation when the volume of paste was above minimum paste volume, but showed quality problems when it was below minimum paste volume due to serious bleeding and material segregation.

5) Analysis of correlation between drying shrinkage and minimum paste volume of concrete indicated no correlation and the compressive strength of concrete showed similar characteristics at minimum paste volume regardless of the type of aggregates.

\section{References}

1. Fowler, D. and Koehler, E., Aggregates in Self-Consolidating Concrete, ICAR Project, Research Report ICAR 108-2F, 2007.

2. Glavind, M., Olsen, G. S., and Munch-Petersen, C., Packing Calculations and Concrete Mix Design, Nordic Concrete Research, Publication No. 13., 1993.

3. Golterman, P., Johansen, V., and Palbfl, L., "Packing of Aggregates : An Alternative Tool to Determine the Optimal Aggregate Mix", ACI Materials Journal, Vol. 94, No. 5, 1997, 435 pp.

4. Quiroga, P.N. and Fowler, D., The Effects of Aggregates Characteristics on the Performance of Portland Cement Concrete, The University of Texas at Austin, Report ICAR 104-1F, 2003.

5. Tu, T.Y., Chen, Y.Y., and Hwang, C.L., "Properties of HPC with recycled aggregates", Cement and Concrete Research, Vol. 26, 2006, pp. 943 950.

6. Lafrenz, J.L., "Aggregate Grading Control for PCC Pavements : Improving Constructability of Concrete Pavements by Assuring Consistency of Mixes", Fifth Annual International Center for Aggregates Research Symposium, Austin, Texas, 1997.

7. Shilstone, J.M.Sr., "Concrete Mixture Optimization", Concrete International : Design and Construction, Vol. 12, No. 6, 1990, pp. 33 39.

8. Shilstone, J.M.Sr., "Changes in Concrete Aggregate Standards," The Construction Specifier, July, 1994, 119 pp. 